\title{
EDITORIAL
}

\section{El estado de la práctica Gineco-Obstétrica, un parangón en 30 años de ejercicio profesional}

"Me han encomendado que en esta sesión solemne de la Sociedad Bogotana de Obstetricia y Ginecología dirigir a ustedes unas palabras relacionadas con "El estado de la práctica Gineco-Obstétrica, un parangón en 30 años de ejercicio profesional", gracias al nombramiento de algunos de nosotros como Miembros Eméritos de la misma.

Al recibir este nombramiento y este encargo, se despiertan en mí una serie de recuerdos y una multitud de cosas vienen a la memoria y desordenadamente me hacen ver que por más de 30 años he venido ejerciendo dentro de la Sociedad diversas labores que en su momento ella me ha encomendado; me recuerda también que de soldado raso fui ascendiendo hasta ocupar los más altos honores, al haber sido elegido como Presidente por dos períodos (1980 y 1981) y además, por haber sido elegido como Presidente de la Federación en el periodo de (1984-1985); la película se va desarrollando y nos muestra cómo en estos últimos años la especialidad ha tenido el más alto progreso, ha tenido los cambios más radicales y el desarrollo que nunca hubiéramos imaginado los que comenzábamos a ejercer la profesión en esta segunda mitad del siglo XX. Los cambios han sido radicales en el conocimiento, en el desarrollo cientifico, en el desarrollo tecnológico y en el ejercicio profesional tan influenciado últimamente gracias a la ley 100, y qué decir del cambio en la enseñanza de nuestras disciplinas que, gracias al progreso en todo sentido, ha hecho que se haya modificado substancialmente la docencia en pre y postgrado.

Veamos en primer lugar cómo al principio de los años 50 vino la revolución educativa de la enseñanza de la Medicina que venía siguiendo el modelo francés y fuimos cambiando al modelo norteamericano; uno de los primeros resultados fue el que nuestras antiguas disciplinas de Ginecología y Obstetricia que eran independientes y se ejercían de esa manera, se unieran, y siguiendo el modelo dicho, se volvió la Ginecología y la Obstetricia una sola especialidad, hecho fundamental que inició el cambio en la enseñanza, pues por tradición, se enseñaba la Ginecología y la Obstetricia en cátedras independientes y a partir de los años 60 se fundieron y se dio a la docencia esa nueva perspectiva. Pero ese no fue el único cambio que se suscitó con relación a la enseñanza, porque con todo el progreso de la tecnología y con el cambio en el ejercicio profesional, en este momento hemos tenido que cambiar el currículum de nuestra especialidad $y$ adaptarla para que los nuevos especialistas estén preparados para ejercerla en el siglo XXI.

También hemos tenido cambios enormes en el ejercicio mismo de la profesión; en esa época la obstetricia era un arte y una ciencia; primaba la clínica y la atención del parto, era un arte que procuraba a ultranza entenderlo por las vías naturales y solamente y en muy escaso porcentaje intervenía el especialista conduciendo un parto instrumentado, el parto con los fórceps que en este momento se ha visto desplazado por las espátulas (es excepcional que en nuestro medio se usen los fórceps y también se enseñe a usarlos; actualmente las nuevas generaciones se han formado en la era de las espátulas) y qué decir de las cesáreas: al principio de los años 60 no pasaba el porcentaje de cesáreas del 1,5 al 10\% según diferentes estadísticas. En las instituciones como el Instituto Materno Infantil, y el Hospital de San José, las cesáreas ocupaban sólo un 2 al 3\% para ver qué sucede ahora con el advenimiento de la tecnología, de la monitoría intraparto, que llegaron a nosotros, gracias a las enseñanzas de la escuela de Montevideo, con los recordados profesores Caldeyro y Alvarez. Ante las desaceleraciones, o cualquier indicio de sufrimiento fetal, inmediatamente se pasa a la sala de cirugía a la paciente, se le aplica la anestesia peridural y se le practica la operación cesárea. Ha llegado esta situación entre nosotros a tal extremo que se abusa de esta intervención y en las clínicas privadas el porcentaje de cesáreas alcanza fácilmente al 50\%; en otras latitudes como en el Brasil, en algunas clínicas de Sao Pablo se llega al 80\%. Cierto que vivimos otras épocas, que el diario vivir, la velocidad, el tiempo y que todos los factores hacen que se resuelvan las situaciones de una manera más rápida, ya no es común observar a alguien haciendo una conducción de parto de 6, 8 ó más horas como muchas veces lo hicimos antaño. Ahora no, y uno se pregunta si ha desaparecido el arte de la atención 
obstétrica, ha desaparecido la paciencia, o es que por facilismo, por tiempo, por la angustia médica y por la distocia del obstetra, hemos llegado a esto que yo considero un exceso.

Es tal la situación, que el ingenio cachaco ha levantado el cuento de que un colega al llegar a una de las clínicas privadas de Bogotá encontró un enorme barullo; todo el mundo corría; médicos, enfermeras, etc., se agolpaban en una sala obstétrica; al indagar porqué razón lo hacian, le contestaron "es que se está atendiendo un parto vaginal"; eso naturalmente que es una exageración y un cuento derivado de la agudeza de los bogotanos, es una cosa que hemos visto llegar y que no va a mejorar en el futuro; algunos dirán que la tecnología con la monitoría intra parto está haciendo evidente una serie de situaciones que antiguamente y por la clínica muchas veces nos demorábamos en diagnosticar, por ejemplo el sufrimiento fetal; los partidarios de la operación cesárea van a alegar que quizá niños de los que nos empecinábamos en atender su parto por vía vaginal nacian con defectos que a la larga se manifestaban por retardos mentales, sordera, etc.

En los años 60 la preparación y la atención para la mujer en su embarazo y en su parto quizá era mucho más personalizado; en esa época de apogeo brilló el estudio y la aplicación de la sicoprofilaxis obstétrica, que en el momento actual se ha venido a menos, pues, en vista de que un enorme porcentaje de casos se resuelven mediante la operación cesárea, ha dejado de cumplir con su objetivo que era tener un parto natural, en mejores condiciones para la madre y el feto.

Otro campo que se ha desarrollado de una manera verdaderamente increible es el del laboratorio, con el perfeccionamiento de las pruebas diagnósticas, como por ejemplo, la más simple de todas para el diagnóstico del embarazo: la reacción de Galli Mainini de los años 50 ha perdido toda vigencia gracias a las reacciones inmunológicas y a los anticuerpos monoclonales para detectar la HCG Beta, pruebas que pueden ser positivas, tan precoces como antes del primer dia del retardo menstrual.

Otro aspecto relacionado con el del laboratorio clínico que ha tenido enorme desarrollo es el de la endocrinología y los estudios hormonales. En los años 50 se hablaba lógicamente de los estrógenos, de la progesterona, de la prolactina y de las hormonas gonadotropas y en esa época decíamos que el director de la orquesta endocrina era la hipófisis; qué enormes cambios y conocimientos hemos adquirido en el transcurso de todo este tiempo. Hemos podido conocer el hipotálamo endocrino, hemos podido llegar a individualizar las hormonas liberadoras, los análogos de estas hormonas tan útiles, tratar algunas afecciones ginecológicas en el desarrollo de los estudios de infertilidad y de la reproducción asistida.

A propósito de la reproducción asistida, quién iba a pensar en los años 50 que, a finales de los 70 , ibamos a tener el primer bebé probeta; cuando el 25 de julio de 1978 sucede el nacimiento de Louisa Brown, gracias a las conocidisimas experiencias del Dr. Edwards y Steptoe. "Bebé probeta" como se le denominó periodísticamente a la fertilización in vitro y a la transferencia embrionaria, fue el resultado de una serie de experiencias y del desarrollo de conocimientos increíbles, pues, se puso de presente con todas esas investigaciones el desconocimiento total que teniamos acerca de la fisiología del ovario; gracias a esta reproducción asistida hemos conocido y descubierto que el líquido folicular no solamente tiene estrógenos, progesterona y gonadotropinas, sino que tiene proteasas y una serie de sustancias que por su acción antagónica y por su comportamiento semejante a nuevas hormonas se denominaron en principio inhibinas, puesto que inhibian la acción hormonal, el crecimiento y desarrollo del folículo, el crecimiento y el desarrollo del oocito; también otras, las activinas que ejercen acciones positivas, acciones estimulantes y que gracias a ese conocimiento de la maduración del ovocito y la cantidad de inhibinas, activinas y folistatinas dentro del foliculo, se logró perfeccionar la técnica hasta el punto que hemos llegado a controlar y disponer a nuestro antojo el fenómeno de la ovulación, el fenómeno de la recolección de los oocitos, para poder favorecer los diferentes métodos de reproducción asistida que estamos viendo que en el mundo se dan.

Ese conocimiento que hemos adquirido con el transcurso del tiempo ha sido enorme, avasallante, hemos llegado a puntos en los cuales en ningún momento hubiéramos podido ni siquiera intuir como es la manipulación de los embriones, la posibilidad de extirpar en el futuro la hemofilia, gracias al estudio de las células del embrión portador de los genes para así poderlos seleccionar. Ese fenómeno de la reproducción asistida que se constituyó en un boon con el nacimiento de Louisa Brown, se vino a cristalizar entre nosotros gracias a la experiencia del Dr. Lucena, con el nacimiento de Diana Carolina, el 11 de enero de 1985. Pero tenemos que pensar en relación a estos problemas de reproducción asistida de todo lo que eso conlleva; no es solamente la parte técnica, parte científica, es la parte ética y moral 
la que nos debe hacer pensar en ¿hasta dónde va a llegar la humanidad en esta evolución? ¿dónde es lícita esa manipulación de los embriones? ¿es licito el conservar los embriones congelados para en un tiempo posterior descongelarlos e implantarlos y hacerlos desarrollar? y ¿qué tan lícito puede ser cuándo algunos de los padres hayan muerto, cuando algunas de las madres ya no existan? ¿Qué se va hacer con esos embriones y qué problemas suscitaría el descongelarlos y llevarlos para que continúen su proceso de formación y desarrollo normal?

Es evidente que no hay legislación clara al respecto aún en los países más desarrollados, los paises que han sido pioneros de estas técnicas. No existe una ley clara, una disposición legal que vaya a aclarar estas situaciones. Asi como hablamos de la reproducción asistida, hablamos del conocimiento actual de la endocrinologia; en los años 60 uno encontraba en los textos, por ejemplo, que la influencia del sistema nervioso en las glándulas endocrinas se debe a factores que modifican el comportamiento, la retroalimentación humoral y los fenómenos psíquicos que son capaces de cambiar la fisiología. El stress, las angustias, las guerras manifestaban evidentemente un a serie de cambios en el aparato genital, amenorreas o metrorragias; no sabiamos en realidad que era lo que sucedia, no habiamos podido identificar lo que ahora es claro que es el papel endocrino del hipotálamo y así, como decíamos que la hipófisis era la directora de orquesta de las glándulas endocrinas, debemos decir que en el momento actual el conocimiento de las hormonas liberadoras ha hecho que el hipotálamo sea el que haya cogido este papel y el que verdaderamente lo está desempeñando gracias a ser el receptor de las influencias de la corteza cerebral, etc.

Otros cambios que vivimos de manera muy cercana fue el que se suscitó en nuestro pais con el advenimiento de la planificación familiar y las politicas de población, siendo sus impulsadores y pioneros Hernán Mendoza (Endocrinólogo) y Fernando Tamayo, nuestro colega ginecólogo.

La planificación familiar entendiendo como tal, no a la anticoncepción, sino a todo el proceso que conlleva el que la pareja sea libre de escoger la prole, sea libre de planificar su familia. Esa libertad se ha obtenido gracias a la educación y al enorme desarrollo de los programas de planificación familiar y por supuesto a los métodos de anticoncepción.

Por los años 60, después de las experiencias de Pinkus y de Celso Ramón García, quienes junto con Jhon Rock, fueron los padres de la pildora y la ensayaron por primera vez en Río Piedras, Puerto Rico, vio la luz entre nosotros la primera pildora: el Enovid; nació Profamilia. Como entidad privada ha desarrollado en nuestro medio una campaña verdaderamente importante y logró algunas veces, con la cooperación del Ministerio de Salud, rebajar la tasa de natalidad a los porcentajes que actualmente estamos viviendo; en 1964 el número de hijos por mujer en edad fértil era de 7, en 1990 de 2,8. La tasa de natalidad de 45 bajó a 26 por año y por mil; el crecimiento de la población de 3.1 bajó a 1,8 y el porcentaje de mujeres en edad fértil y en unión que usaban anticonceptivos del $20 \%$ en el año 64 pasaron a 66\% en el 90, asi el aporte de Profamilia, de la Corporación del centro regional de población, de la Asociación Colombiana para estudio de la población y de otros organismos que se me escapan, ha sido verdaderamente importante y han demostrado que en el curso de estos últimos 30 años su labor no ha sido estéril y se han obtenido verdaderos logros.

Hemos podido ver que la ginecología hacia los años 40 era esencialmente una ginécología quirúrgica, una ginecología operatoria y que a la paciente que necesitaba una intervención quirúrgica se la practicaban los cirujanos y paulatinamente con el transcurso del tiempo la Ginecología asi como la Obstetricia, han dejado de ser la una "quirúrgica" y la otra "partera" para volverse verdaderamente una ciencia desarrollada, gracias a todos estos adelantos que hemos anotado, como el diagnóstico prenatal, los adelantos en endocrinología, el conocimiento adquirido de los aspectos científicos relacionados con la mujer. El conocimiento y la comprensión del comportamiento inmunológico en el embarazo (injerto halo inmune) y su influencia en el aborto.

Hablemos de la cirugía, que era hasta hace poco tiempo, a cielo abierto con las técnicas más depuradas, con la elegancia de nuestros ilustres maestros, en este momento ha entrado en boom la cirugia video laparoscópica; ya no se piensa, salvo casos complicados, (como un hemoperitoneo, uno de schock), tratar un embarazo ectópico a cielo abierto, ahora se trata esta entidad por métodos laparoscópicos, cosa que verdaderamente ha demostrado el progreso de las técnicas quirúrgicas, que ha hecho posible precisar los diagnósticos y que ha acortado definitivamente los postoperatorios y el periodo en el cual nuestra mujer está incapacitada para volver a su trabajo. Igual sucede con los tumores de ovario, con la planificación 
familiar por métodos definitivos como la ligadura o sección de las trompas, los tumores pequeños del útero y lógicamente la histerectomía abdominal completa o lo que es más frecuente la histerectomía vaginal asistida por laparoscopia.

En todo eso hemos visto un desarrollo verdaderamente grande y un progreso de la terapéutica quirúrgica, que con el mejoramiento de las técnicas anotadas ven ustedes cómo se están haciendo hasta correcciones de incontinencia urinaria, citopexias, etc. ¿Será que en el futuro quedará campo para las técnicas quirúrgicas tradicionales o éstas serán obsoletas?

Con relación a otros aspectos del ejercicio profesional, no podemos dejar a un lado el meditar la manera cómo hace 30 o más años ejerciamos la especialidad, cuando básicamente nuestra manera de vivir, nuestro futuro económico estaba basado en el libre ejercicio de la profesión, tanto que en las entidades hospitalarias regalábamos nuestro trabajo; generalmente la practica privada era lo suficientemente buena para permitir nuestra normal subsistencia, pero las instituciones solo trabajaban por la mañana.

Ahora hemos tenido un cambio radical porque estamos gobernados por las EPS, estamos obligados a ejercer una medicina rápida y ojalá a los menores costos, nos controlan, nos vigilan y nos auditan los exámenes de laboratorio, los exámenes paraclínicos, etc., casos se han dado que a algunos de los colegas no les han vuelto a enviar pacientes "porque esos doctores piden muchos exámenes y ocasionan muchos gastos".

El ejercicio de la medicina se ha vuelto tan impersonal, se ha vuelto tan difícil que estamos sometidos a permanentes demandas de responsabilidad civil, a demandas penales, a tutelas, lo que hace que estemos a la defensiva. No tenemos pacientes sino usuarios, nosotros no ejercemos una profesión liberal sino que somos operarios, somos empleados y por esta razón también tenemos que vivir a la defensiva. Como dice el Dr. Anibal Acosta al hablar en la reunión inaugural del grupo Latinoamericano de la Sociedad Americana de Fertilidad: "además de las complejidades tecnológicas, de las incertidumbres éticas, de las profundas repercusiones familiares y aún socinles, de las técnicas de reproducción asistida y de las complejidades legales a las que no hace falta siquiera hacer referencia, han surgido ahora otros problemas de diferente carácter pero de similar magnitud. Los actos médicos no son juzgados solamente como tales y por pares; terceras personas ajenas a la esencia de nuestras preocupaciones e inquietudes han ingresado en la escena".

Entrando a otro tema, hemos visto durante estos 30 largos años, cómo ha cambiado la Sociedad Colombiana de Obstetricia y Ginecología, como su labor evidentemente se ha venido adecuando a las necesidades en que se vive, el número de socios ha pasado a varios centenares, el desarrollo de los Congresos y los eventos Cientificos ha tenido un crecimiento desmesurado; de 224 asistentes al primer Congreso que se efectuó en Bogotá en el año 1953 pasamos a un número de más de 1500 asistentes, como en el último congreso en la ciudad de Medellín, porque el interés científico evidentemente se ha acrecentado; antiguamente teníamos celebraciones de uno o dos eventos al año, teníamos el congreso nacional cada dos años y ustedes ven como es perfectamente imposible en el momento actual estar al tanto de todas las actividades científicas que se desarrollan en nuestro medio tanto que ya no solamente son de una enorme frecuencia sino que se interponen unas con otras; al mismo tiempo en dos o tres sitios de la ciudad se están desarrollando eventos cientificos relacionados con la especialidad. Eso nos da a entender que la Sociedad Colombiana de Obstetricia y Ginecologia ha adquirido cada vez una fuerza mayor.

Después del año 64, en que se formó la Federación Colombiana de Sociedades de Obstetricia y Ginecologia, esa hermandad entre todas las sociedades del pais se fue acrecentando, hemos sido lideres en nuestro país y fuera de él en nuestra disciplina; hemos sido líderes del Grupo Bolivariano de la Flasog, gracias a la labor desarrollada desde hace algunos años cuando se celebró la primera reunión del grupo a la cual asistimos en la ciudad de La Paz, Bolivia, luego nos reunimos en Caracas; desde entonces ha habido repetidas reuniones, tanto es asi que en este momento nuestra vicepresidenta, la Dra. María Teresa Peralta, está liderando este grupo y tendremos para el año entrante la reunión conjunta, junto con el bienal que viene de tiempo atrás desarrollando la Sociedad Colombiana de Obstetricia y Ginecología.

Hemos dado un vistazo de lo que ha sido la especialidad y el desarrollo en nuestro medio, gracias al progreso en la reproducción asistida, en el conocimiento de la endocrinología, de la planificación familiar $y$ del arte quirúrgico. 
Estamos en primera línea; en el diagnóstico prenatal hemos alcanzado metas que antes no pensábamos que pudiéramos lograr; el diagnóstico y el tratamiento de las malformaciones congénitas están al orden del día y estamos a punto de erradicar todos los problemas relacionados con la iso-inmunización Rh y muchos otros que sería largo enumerar, hechos que dicen que en este momento hemos alcanzado una altura, una exquisitez y una finura en nuestros conocimientos que verdaderamente asombran.

Queridos colegas, estamos recibiendo el título de eméritos, lo que significa que ya hemos cumplido con la sociedad, con nuestras mujeres, con nuestros discipulos, que hemos contribuido en una u otra forma al progreso de la especialidad, a la formación de nuevas generaciones de médicos; estamos como dice la frase de cajón "con el sol a nuestras espaldas". Debemos estar orgullosos por el deber cumplido; creemos que verdaderamente hemos contribuido al progreso y a enaltecer nuestra especialidad; esperamos haber sido ejemplo muy significativo y que en la noche de hoy, al dejar nuestros sillones como miembros de número, vengan nuevas generaciones a reemplazarnos. Quiero decirles a estos doctores, a estos colegas especialistas que hoy reciben su título de miembro de número de la Sociedad, que ahí les entregamos una institución fuerte, que les entregamos el campo para que hagan que nuestra especialidad alcance los límites máximos. Para la actual junta directiva de la Sociedad Colombiana de Obstetricia y Ginecología, los doctores Jairo de la Cruz, la Dra. María Teresa Peralta, al Dr. Jairo Iván Gómez, al Dr. Carlos Zamudio, al Dr. Oscar Angel y al Dr. Alvaro Guzmán, van mis agradecimientos y me hago vocero de todos los compañeros que conmigo reciben hoy su título de miembros eméritos de la Sociedad, para decirles que permaneceremos en la brega y que continuaremos dispuestos a servirle a la sociedad y servirle a Colombia.

No quiero terminar sin rendir un homenaje sentido a todos nuestros profesores, los que ya se han ido y los que para fortuna nuestra aun nos acompañan, sembraron semillas que ahora hemos cosechado y gracias a su ejemplo llegamos a donde estamos." 